\title{
Policies and Practices of Health Promotion in Nepal
}

$\sim$ Binod Kumar Karki $^{1}$

\begin{abstract}
Health promotion is the process of enabling people to increase and improve their health. Health Promotion has globally emerged as a separate stream of public health but in Nepal it is still a relatively new concept. There are challenges related to research in the field of health promotion. Health promotion requires policy makers across all government departments to make health a central line of government policy. The aims of this study is to discover key policies and strategies of health promotion in Nepal and to identify the different activities and practices carried out by them. This study is based on review of the national health policies that were published in different period of time. The paper argues that health promotion requires policy makers across all government bodies to make health a central line of government policy since health policy is one of the most important aspects of the livelihood development of a country.
\end{abstract}

Keywords: Health Promotion, Policy, Practice, Low Literacy, Health Care

\section{Introduction}

Health promotion is the process of enabling people to increase control over the determinants of health and thereby improve their health (WHO, 1986). It covers a wide range of social and environmental interventions that are designed to benefit and protect individual people's health and quality of life by addressing and preventing the root causes of ill health. Health is a fundamental human right. The constitution of Nepal 2072 say: Every citizen shall have the right to basic health services from the state; and every citizen shall have equal access to health services.

Health promotion is a term of more recent origin than health education. As defined by Green, it is "any combination of education and related organizational, economic and environmental supports for behavior of individuals, groups or communities conductive to health (Green \& Kreuter, 2005). The area of public health that has silent role in dealing with these challenges is health promotion. However, health promotion as an area has its own burdens.

Health promotion requires policy makers across all government departments to make health a central line of government policy. This means they must factor health implications into all the decisions they take, and prioritize policies that prevent

1 Karki is an Assistant Professor at Koteshwor Multiple Campus (KMC). He teaches Population and Health to the students of Bachelor-level at KMC. 
people from becoming ill and protect them from injuries. People need to acquire the knowledge, skills and information to make healthy choices, for example about the food they eat and healthcare services that they need. They need to have opportunities to make those choices. And they need to be assured of an environment in which people can demand further policy actions to further improve their health. Communities have a key role to play in promoting good health. Strong leadership and commitment at the grass-root level is essential to healthy planning and to build up preventive measures in communities and primary health care facilities. From healthy communities evolve healthy countries and, ultimately, a healthier world.

Health promotion today has globally emerged as a separate identifiable stream of public health. However, in Nepal, health promotion is still a relatively new concept. Focusing an individual level or disease prevention is an outdated concept, the new concept of public health, usually called new public health or health promotion covers wide range of public health related issues (Digital, 2018). Public health and health promotion both are important to all the people. Public health is mainly focus prevention of diseases at individual level but health promotion focuses community improvement through collective effort.

Who is responsible for health, the individual or society? It is inevitable that person's lifestyle has an immense impact on his/her health. Health is not created and lived in isolation. It results from an ongoing process and interaction with the individuals' socio-ecological environment throughout the whole life. In this context, we all have to function as active participating subjects in our own life, making use of sources in order to maintain and improve health. Thus, health can be seen as a lifelong learning process where we reflect on what will create health and what are the options for life and quality of life.

Health is perceived and evaluated differently by the individual across the span, and highly depends on factors within the individual, but also on factors in the individuals close and distant environment. Health and well-being is significantly influenced by the circumstances of our lives, access to services, work and income and by the communities where we live as well as our own lives. Therefore, the knowledge base of health promotion as well as strategies to promote health must be there in our communities. Given the complexity of health promotion practice, multilevel, comprehensive interventions are needed to develop effective programs. It is vital to consider psychological, organizational, cultural, community level, political and policy driven factors that influence health. Theories provide a road map and a step by step summary of what factors to consider when designing, implementing and evaluating a health promotion program. It is vital to have theoretical understanding of why people behave the way they do.

Health promotion needs to be based on several types of knowledge. The public health development for the population to be served, background contextual information about 
the political situation, historical, cultural and economic conditions and knowledge relevant for implementation of health promotion.

Health promotion is a vital component of public health practice. During last two decades, health promotion has been consolidated and institutionalized. Public health practitioners, policy-makers, academicians and researchers recognize the role of health promotion in improving public health. Many professional associations and scholarly journals are working in the area of health promotion (Potvin \& Jones, 2011). In 2009, health promotion was re-defined as, "Health Promotion is the art and science of helping people discover the synergies between their core passions and optimal health, enhancing their motivation to strive for optimal health, and supporting them in changing their lifestyle to move toward a state of optimal health. Optimal health is a dynamic balance of physical, emotional, social, spiritual, and intellectual health. Lifestyle change can be facilitated through a combination of learning experiences that enhance awareness, increase motivation, and build skills and, most important, through the creation of opportunities that open access to environments that make positive health practices the easiest choice"(O’ Donnell, 2009).

Health promotion has positively impacted public health practices. A number of public health achievements are attributed to health promotion. Ten great public health achievements of the last century include vaccination; motor-vehicle safety; safer workplaces; infectious diseases control; decrease in mortality due to coronary heart disease and stroke; safer and healthier foods; improved maternal and child health; family planning; drinking water fluoridation; and recognition of health hazards of tobacco use (United States, 1999). None of these achievements would have been possible without health promotion. Health promotion is a means to an end, and enables people to take action. Health promotion needs to be done in collaboration with people and requires their participation or partnership. It helps groups and communities in strengthening their skills and their capacity to take actions which support healthy lifestyles. They act collectively resulting in empowerment of individuals which is a valued outcome of health promotion (Nut beam, 1998).

A number of governments around the world are committed to health promotion for their countries. International organizations such as the World Health Organization has responded to the commitments of their member countries by providing support in health promotion and in developing policies, programs and activities related to health promotion (Rice, 2012). Health care visits for various purposes are opportunities for health promotion activities. It is especially important in case of maternal health where women report routinely for antenatal care. These visits can be utilized to promote health in this vulnerable group of population (Moos, 2002). Visits for childhood vaccination and growth monitoring can be utilized for health promotion to improve health of children and young adults. Follow-up visits of patients with chronic disease also provide an opportunity for health promotion activities. 
A valuable opportunity for promoting health arises from the availability of advanced technology and electronic means of communication. The internet has broadened the scope of health care beyond its traditional boundaries. Mass media has an important role in promoting health. Social media can communicate the health messages to a wider, diverse group of audience.

There are multiple challenges associated with health promotion. Many countries lack capacity for health promotion practice. An important challenge is to build capacity of the workforce, organizations and infrastructure for health promotion (Potvin \& Jones, 2011). Another challenge for health promotion is vested interest of various groups. Influential industries like food chains selling junk 'food'; alcohol and tobacco industries; have their vested interests (Livingstone, 2011). There is increasing recognition of role of ethics in health promotion. It is argued that health promotion should be based on practical reason which helps in reflecting on the benefits and purpose of health promotion. The purpose of health promotion should be to engage individuals to reason about what they value and how they can adopt these values. To achieve this purpose, specific responses to local situations are required instead of treating all communities in the same way (Carter, 2012).

A major challenge for the future is to develop and maintain the trust of communities, especially the socially marginalized in society. In the global conditions of growing inequality and poverty, the socially marginalized, such as youth and migrant groups, may not be receptive to messages related to health promotion (Lave rack \& Keshavarz, 2011). It will take some time and need to have dialogue with the local communities and provision of good quality, need-based services to the communities. Varying strategies will be needed for various groups in different cultural contexts. Increasing life expectancy and natural and man-made disasters has leads to growing number of people with disabilities. Improving the quality of life of people with disabilities by health promotion should also become a major focus for public health practitioners (Rummer, 1999).

There are challenges related to research in the field of health promotion. There is lack of implementation of evidence in health promotion practice and lack of application of evidence while formulating policies (Potvin \& Jones, 2011). There are technical problems in evaluation of health promotion projects. For conducting evaluation of health promotion projects, it is important to define and measure the outcomes of health promotion. Appropriate methodologies for evaluation of health promotion projects need to be designed and adopted (Nut beam, 1998). To improve the quality of researches in the area of health promotion, researchers, funding agencies, and review and editorial boards of scholarly journals need to take appropriate measures (Glasgow et al., 2004).

Nepal is an underdeveloped country, located between India and China. The country 
is divided into three regions geographically: Mountains, the Terai and Hills. Due to geographic, topological and socio-cultural factors, Nepal has been deprived of economic development. Furthermore, the health of the population is in very poor condition. Both communicable and non-communicable diseases are the major cause of mortality and morbidity. Acute preventable childhood diseases, complications of child birth, nutritional disorders, malaria, kalazar, tuberculosis, leprosy, STDs, rabies, and vector borne diseases are increasingly high (MOHP, 2009). Additionally, other health problems like mental health, oral health, hearing impairment, blindness, HIV/AIDS, cardiovascular diseases, diabetes, hypertension, malignancies and elderly problems are also affecting the country (WHO, 2007). Poverty, low literacy rates, low level of hygiene and sanitary facilities, limited safe drinking water, tobacco use, excessive use of alcohol, less physical activity, obesity, poor nutrition and polluted environment are the major causes behind the poor status of health among the Nepalese people (WHO 2007, MOHP, 2009). Other conditions include limited resources (man, money and material) and poor infrastructure, poorly managed organization and low co-ordination (MOHP, 2009).

Health promotion is most commonly defined as 'the process of enabling people to increase control over the determinants of health and thereby improve their health'. Health promotion today has globally emerged as a separate identifiable stream of public health. However, in Nepal, health promotion is still a relatively new concept. No studies have been conducted so far to explore the kind of health promotion initiatives and approaches being undertaken in Nepal.

Hence, the aims of this study are to identify key policies and strategies in health promotion of Nepal and to identify the different activities and practices carried out by them. This study has been focused on the position of health promotion in the different health policies in Nepal.

\section{Methodology}

This study has included a review of national health policies to understand the status of health promotion in policy, planning and practices. I have used systematic review in health policies and strategies to obtain information regarding two research objectives. There were no any participants directly involved in this research because this research has been based on secondary sources. The study has been conducted through using secondary data. The health policies and strategies included are the National Health Policy (1991), The Second Long Term Health Plan (1997-2017), National Safe Abortion Policy (2002), National Nutrition Policy(2004), Nepal Health Sector ProgrammerImplementation Plan (2004-2009), Nepal Health-sector Programmer-Implementation Plan II (2010-2015),National Health Communication Policy (2012), National Health Policy (2014) and Nepal Health Sector Strategy (2015-2020). 


\section{Interpretation}

Health promotion enables to increase control over their health. It covers a wide range of social and environment intervention that are designed to benefit and protect individual people's health and quality of life by addressing and preventing the root causes of ill health, not just focusing on treatment and cure. Health promotion requires policy makers across all government departments to make health a central line of government policy. This means they must factors health implications into all the decisions they take, and prioritize policies that prevent people from becoming ill and protect them from injuries. The Health Policy is one of the most important aspects of development of health of a country. It is important in a country like ours where resources and technology are more limited than in other countries.

Ministry of Health and Population of Nepal has been actively embedding health promotion goals and processes in national and international health strategies, policies and practices to overcome different health problems. The study was carried out with systematic review of health policies, strategies and practices. The emergent themes from review included: a) Health Policies and b) Health Practices

\section{Health Policies}

In 1991, a National Health Policy was adopted to improve the health of the people. One of the areas addressed by this National Health Policy was the promotive health services. Promotive health service is program that enable people to live healthy lives will be given priority. The service includes such practices which are aimed not only at destroying the factors that may lead to specific disease but also at raising the health condition of the people to its maximum level. It includes health education, balanced diet, healthy living, regular health checkup, family planning and maternal and child health. In this service, different components of health are included, namely, health education, nutrition program and environmental sanitation program. Second Long Term Health Plan, 1997-2017 has mentioned that National Health Education, Information and communication Centre (NHEICC) is a focal point for Ministry of Health and Population for Planning, implementation, monitoring and evaluation of health promotional activities. The plan clearly state that NHEICC is responsible for the development, production, dissemination, publication and distribution of correct health messages through appropriate communication media in collaboration with other departments, divisions and centers.

Nepal Safe Abortion Policy, 2002 enactment of safe abortion law in Nepal. Many women were incarcerated for different durations for abortion related crimes as the act of abortion was considered a criminal act in Nepal before its legalization in March 2002 AD. Even though the new abortion law legalized the abortion under specified 
condition the ingrained fear and stigma still prevails in the society and many women were still terminating pregnancy by unskilled persons to maintain privacy and secrecy. National nutrition policy, 2004 is another milestone for health promotion in Nepal. Adequate nutrition is a fundamental right of every human being. Improving the nutritional status of people is one of the prime duties of the government and is an essential factor in improving their health status and the quality of life.Nepal Health Sector program Implementation Plan I, 2004-2009 had recognized and accepted health communication as a cross cutting issue for all health programs. It has stated that behavioral change communication program to support essential health care service package. Nepal Health Sector Program-Implementation Plan II, 2010-2015 has prioritized and included public health promotion programs under health education and communication heading.

Similarly, National Health Communication Policy, 2012 is the milestone for health promotion, education and communication program under Ministry of Health and Population. It shows that government of Nepal has given high priority to health promotion, education and communication program in the health sector. It has given priority to issues related to control lifestyle related diseases and encourage improving daily lifestyle of human from simple behavior of individual. National Health Policy 2014 has been formulated to protect the achievement made so far and to adequately address prevalent and new challenges faced within health sector by developing people centered and efficient management by optimal utilization of available means and resources to provide promotive, preventive, curative and rehabilitative health services.

Nepal Health Sector Strategy, 2015-2020 is the latest plan. It is the primary instrument to guide the health sector for the next five years. It adopts the vision and mission set forth by the National Health Policy and carries the ethos of constitutional provisional to guarantee access to basic health services as a fundamental right of every citizen. It is recognized as the strategy that will guide the sector, taking into account multi-sector collaboration to address social determinants of health, over the next five years period.

\section{Health Practices}

The National Health Policy1991, has given ultimate mandate to Health Education Information Centre authority, to plan manage and implement health education and promotion program to encourage people to utilize best the health services so that their health standard would be upgraded by themselves and ultimately achieved productive, happiest and long life. National Health Education Information and Communication Centre (NHEICC) were established in 1993 AD. The Centre has been working as an institution for planning, implementation, monitoring and evaluation of advocacy, community mobilization and behavior change communication programs of all health services and programs at different levels in a coordinated approach and through one 
door system. Health education adopters are expected to inform, encourage, persuade and motivate to have positive behavior changes in the specific audience and to adopt healthy behavior.

Nepal Safe Abortion Policy has gradually paved its way in our nation. Safe abortion care is integrated in safe motherhood program of Nepal to make it more accessible and acceptable. Safe abortion service is scaled up in all the districts up to primary health care center level. National Nutrition Policy clearly described how child and maternal underweight are the greatest risk factors that affect people's health and disease status. In order to reduce nutritional problem, the government of Nepal carried out different programs. Basis of nutrition policy and guiding principles were explained which are very important and indispensable for the implementation of all the nutrition activities and for the development of nutrition programs. Furthermore, the general strategies for all the nutrition programs are profiled to explain the concepts.

Nepal Health Sector Program Implementation Plan-I, has also stressed on the importance of behavioral change communication to address non communicable disease risk factors emphasizing on the reduction of tobacco and harmful use of alcohol. It has mentioned about integrating information education and communication in all essential health care service package and to use all possible mass communication media for health promotion. National Health Sector Program-Implementation Plan-II has emphasized on planning, implementation, monitoring and evaluation of advocacy, social mobilization and behavior change communication programs in an integrated manner to promote and increase utilization of all essential health services and programs, and control communicable and non-communicable diseases. The plan has focused on promoting healthy behavior by using all possible multi-mass media and channels for health promotion and communication.

National Health Communication Policy emphasizes quality health promotion and communication by developing and producing manpower related to health promotion and communication. The various types of problems and challenges have been faced in effective implementation of health promotion, education and health communication programs. Access and utilization of essential health services to mass people particularly people living in remote village, disadvantage, poorer and marginalized population have been deprived due to not having adequate access to health promotion and communication program and services.

Health Policy 2014 provided prevention and promotional health services and primary health care service have strengthened over the years and have reached to every citizen. Even though, private sectors are involved mainly in urban cities and are mainly focused in curative care, their involvement and contribution to the health care services have grown and improved over the years. Various agencies have been established to regulate 
and ensure the quality of human resources produced, medicine supplied and researches conducted. General awareness regarding health has also increased. Development in the field of education, communication, transportation, agriculture and food supply has contributed on health promotion and progress. Nepal Health Sector Strategy 20152020 is based on the expanded policy and monitoring framework of National Planning Commission and has also embodied the essence of the National Health Policy-2014. The policy and strategy recognizes the importance of creating a healthy environment and promoting healthy lifestyle choices by people.

\section{Conclusion}

Based on above discussion, it is concluded that health promotion is a sensible strategy for all the people. Health comprises all aspect of life; physical, psychological, social and existential aspects. Health promotion should therefore be directed towards actualizing the health potential in all these interconnected aspects regardless. Further, health promotion is closely linked to well- being and quality of life with potential positive impacts on health. Most of our health is created in our society, but good health and ill health are persistently unequally distributed. Effective plan and policies as well as appropriate health care practices are necessary for health promotion of all people. The health policy is one of the most important aspects of development of health of a country. It is particularly important in a country like Nepal where resources and technology are more limited than in other countries. The development of health policy is also a dynamic process, periodical revisit of the policy, its consultations, discussions with fruitful debate updates and continuous works help achieve its goals. The policy recognizes the challenges of consolidating the principles of the previous health policy in community involvement, improved health services provision, access and equity while addressing the different dimensions of reforms that are taking place in the public sector.

The major barriers to promote the health of the population in Nepal result from the lack of infrastructure, limited resources, inequity, socio-economic differences and poverty.

Human beings cannot perform well until the basic requirements are fulfilled. Due to a lack of knowledge and awareness regarding healthy practices, community people are more vulnerable to acquiring diseases, and there is also a lack of properly trained health personnel who can provide appropriate information. Health promotion focuses on community participation and empowerment, but in Nepal there is less community participation and inadequate awareness programs. Furthermore, political instability has caused health promotion programs to be delayed, and these programs are either inadequate or neglected by the government. Also, there is a lack of inter-sectoral coordination between different organizations and inadequate supervision, monitoring and evaluation of health promotion programs. Moreover, increasing population, 
urbanization, environmental pollution and new health problems pose further barriers for promoting health.

Health promotion focuses on political, economical, social, cultural, environmental, behavioral and biological conditions. Therefore, health promotion should be integrated with different disciplines and co-ordination/collaboration from government, public, private,community, universities, national and international sectors is required. With increasing globalization and change in lifestyle, people are facing more challenges to survive in this world. In addition, the increasing gap between rich and poor is making it more difficult to improve peoples' health. Getting health services is becoming expensive, and in countries like Nepal where almost the people are living under the poverty line, it's very hard for them to access health facilities as all the health expenses are paid from one's own pocket. Hence, it is the responsibility of every sector to put healthy public policy into practice, strengthening structures and processes, applying knowledge-based practice, building a competent health promotion work-force and empowering communities.

National health policies, strategies, and plans play an essential role in defining a country's vision, priorities, budgeter decisions and course of action for improving and maintaining the health of its people. Most countries have been using the development of national health policies, strategies and plans for decades to give direction and coherence to their efforts to improve health. The effective long term outcome of any health policy depends to the large degree on the political will of the national authorities and broad understanding of the actual determinants of health. During the last two decades in particular, significant improvement has been noted in health promotion and outcomes.

\section{References}

Carter, S. (2012). What is health promotion ethics? Health Prompt J Austr 23, 4.

Department of Health Services, (2004). National Safe Abortion Policy-2004. Ministry of Health, Kathmandu, Nepal.

DHS, (2004). National Nutrition Policy and Strategy. Ministry of Health, Kathmandu, Nepal.

Dhital, S. (2018, January, 8). Health promotion: Time to adopt new approach. The Himalayan Times. Kathmandu.

Glasgow, R. et al. (2004). The future of health behavior change research: what is needed to improve translation of research into health promotion practice? Ann Behav Med 27, 3-12.

Green, L. W. \& Kreuter, M.W. (2005). Health program planning. An educational and ecological approach (4th ed.). Boston: McGraw- Hill. 
Laverack, G. \& Keshavarz, M. (2011). What remains for the future: strengthening community actions to become an integral part of health promotion practice. Health Promot Int 26, 258-262.

Livingstone, C. (2011). Advocating for public health: does the real world matter? Health Promot J Austr 22, 4-5.

Ministry of Health and Population, (1991). National Health Policy-1991.Ministry of Health and Population,Kathmandu, Nepal.

MoHP, (1997). Second Long Term Health Plan 1997-2017.Health Sector Reform Unit, Kathmandu, Nepal.

MoHP, (2004).Nepal Health Sector Programmer Implementation plan 2004-2009. Ministry of Health, Kathmandu, Nepal.

MoHP, (2009). Finding of a rapid assessment. Free Health Care in Nepal. Ministry of Healthand Population, November, 2009.

MOHP, (2010). Nepal Health Sector Program II. Implementation Plan, 2010-2015. Ministry of Health and Population, Kathmandu, Nepal.

MoHP, (2014). National Health Policy-2014. Ministry of Health and Population, Kathmandu, Nepal.

MoHP, (2015). Nepal Health Sector Strategy 2015-2020.Ministry of Health and Population, Kathmandu, Nepal.

Moos, M. (2002). Pre-conceptional health promotion: opportunities abound. Maternal Child Health 6, 71-73.

National Health Education Information and Communication Centre, (2012). National Health communication Policy-2012. Ministry of Health and Population, Kathmandu, Nepal.

Nutbeam, D. (1998). Evaluating health promotion-progress, problems and solutions. Health Promot Int 13, 27-44.

O'Donnell, M. (2009). Definition of health promotion, embracing passion, enhancing motivation, recognizing dynamic balance, and creating opportunities. Am J Health Promot 24.

Potvin L. \& Jones, C. (2011). Twenty-five years after the Ottawa Charter: the critical role of health promotion for public health. Can J Public Health 102, 244- 248.

Rice, M. (2012). Effective global health promotion achievements, tools, and strategies 
used In the Americas over the past decade. Health Promot Pract 13, 313-319.

Rimmer, J. (1999). Health Promotion for People with Disabilities: The Emerging Paradigm

Shift from Disability Prevention to Prevention of Secondary Conditions. Phys Ther 79, 495-502.

United States, (1999). Ten great public health achievements--United States. MMWR Morb Mortal Wkly Rep 48, 241-243.

World Health Organization, (1986). Ottawa Charter for Health Promotion. First International Conference on Health Promotion, Geneva, Switzerland.

WHO, (2007). Health System in Nepal: Challenges and Strategic Options. WHO country office for Nepal. 